\title{
Afetos e resistências: 20 anos de bahianidade do curso de psicologia
}

\author{
Affections and resistances: 20 years of \\ bahianidade at the psychology course
}

Mônica Ramos Daltro

Autora para correspondência. Escola Bahiana de Medicina e Saúde Pública (Salvador). Bahia, Brasil. monicadaltro@bahiana.edu.br

RESUMO | Esse Relato de Experiência apresenta a narrativa de uma professora da Escola Bahiana de Medicina e Saúde Pública que analisa e descreve seu percurso ao longo dos últimos 20 anos, no trabalho de formação de profissionais de saúde. Localiza a experiência engendrando a história do curso de psicologia à história da própria instituição. Discute uma lógica acadêmica-formativa de natureza política transgressora, que propõe a inclusão da subjetividade e da alteridade como exercício no processo de formação ancoradas numa construção discursiva, nomeada como bahianidade. Esta se sustenta no exercício de uma educação de natureza transformadora e mediada por afetos, esses considerados propulsores do fazer docente nos últimos 20 anos nesse contexto acadêmico.

PALAVRAS-CHAVE: Relato de Experiência. Docente. Coordenação de curso. Psicologia.

\begin{abstract}
This report presents the narrative experience of a professor at the BAHIANA - School of Medicine and Public Health that analyzes and describes her journey over the last 20 years in the job of training health professionals. It establishes the experience engendered with the history of the psychology course and that of its parent institution. It discusses a formative logic that aims at transgression because it perceives itself. Such as it recommends the inclusion of subjectivity and recognition/respect to the otherness as a practical experience at the heart of the training process of students. This is anchored in a discursive construct, named bahianidade, based on the exercise of a transformative nature of education and mediated by sensibilities, thus considered propellants of teaching in that academic context.
\end{abstract}

KEYWORDS: Experience report. Professor. Course coordination. Psychology. 


\section{Introdução}

No contexto da pandemia de COVID-19, a partida de Edésio, gentil guardião de um tempo da Escola Bahiana de Medicina e Saúde Pública - EBMSP, me convocou a escrever sobre tão importante locus da minha história. Edésio e Pai Veio, funcionários de apoio ao serviço educacional da Escola, eram "a cara" de uma Bahiana, sorriam, abriam portas, conheciam todos os alunos, professores e seus hábitos de trabalho e transgressões. Os conheci há um pouco mais de 20 anos, localizada no bairro de Nazaré. Era um momento um pouco anterior à implantação do curso de psicologia. Ali funcionavam os cursos de medicina, fisioterapia e terapia ocupacional.

Com 68 anos de história, a instituição viveu muitas mudanças e reconheço que faço parte de algumas delas.

Assisti em outubro de 2020 passada a um conjunto de homenagens prestadas a docentes e parceiros do Curso de Psicologia, no contexto das comemorações de seus 20 anos. Foram todas justas e honrosas as homenagens, mas fiquei pensando... quantos outros se sentiriam merecedores dessas homenagens? Quantos tantos as mereciam. Isso ativou em mim o reconhecimento de um tempo em que esse curso se fez a partir de uma lógica de convivência, e de implantação de uma cultura de trabalho coletivo que perdura até a atualidade. Uma cultura muito peculiar no âmbito do ensino superior. Para chamar a atenção para esse peculiar modo de operar o trabalho docente, numa instituição privada de ensino superior, optei por construir um relato de experiência cujo objetivo é fazer registro histórico de uma experiência elaborada a partir da percepção de uma professora, cuja uma das maiores satisfações, é aprender.

Um Relato de Experiência é uma narrativa científica resultante de um processo de re-memória e elaboração que descreve de maneira analítica uma experiência, que considera o entrecruzamento de processos, simultaneamente coletivizados e singulares. Tratase de uma ferramenta metodológica, que explana a temperatura de uma época, sem ambicionar descrições de verdades (Daltro \& Faria, 2019).
Não pretendo construir uma narrativa descritiva sobre a instituição EBMSP, conceituada organização não governamental, responsável por ter formado mais de $50 \%$ dos profissionais de saúde do estado da Bahia. Nem discutir a história da "Escolinha da Ladeira", como foi conhecida em um determinado período, em que ser estudantes Bahiana significava ter perdido o vestibular na Universidade Federal da Bahia - UFBa.

Arvoro-me, entretanto, a narrar uma versão sobre a passagem do tempo e o movimento dos ventos como profere o poema do Los Hermanos:

"Posso ouvir o vento passar Assistir à onda bater Mas o estrago que faz A vida é curta pra ver" (O vento, Los Hermanos)

Em 20 anos, testemunhei o vento arejar uma tradicional instituição de ensino superior, transformando-a num território de formação de profissionais de saúde ao também fazer fissuras em antigas e rígidas estruturas. Nesse percurso, ventanias e furacões deram suporte a um processo complexo de ressignificação que envolveu mudança de valores e ideologias. O humanismo, enquanto campo filosófico em geral, que fundamentou as Diretrizes Curriculares Nacionais DCNs para a formação em Saúde, ultrapassou os discursos formativos e se disseminou no cotidiano do fazer educação de qualidade. O Ser Humano, bio-psico-social, marcado por singularidades tornou-se protagonista nos discursos educacionais mas também nas relações de trabalho. Nesse cenário, uma nova identidade e imagem institucional se precipitaram mediadas por afetos declarados.

Em um movimento delicado de báscula entre o desempenho econômico, a história e o futuro, se organizaram existências individuais e coletivas que hoje constituem um corpo, observável, nomeado, cultural, sustentado na alteridade e no reconhecimento como território. Um território existencial acima de tudo. (Macerato, Soares \& Ramos, 2014). Portanto, um campo de movências de afetos, de ideias, de práxis, de conflitos e de subjetividades. Essa experiência de deslocamento incluiu a psicologia sobremaneira. 
Apresentada como curso de graduação, como campo de conhecimento e como prática, a psicologia vem sendo nesse período, engendrada nas entranhas da instituição, em suas formas de gerenciar, cuidar, assistir, ensinar e aprender. Uma psicologia com forte leitura crítica da sociedade e do campo da saúde, compondo um cenário educacional progressista, na direção do que bell hooks (2017) denominou de pedagogia engajada. Tal pedagogia, segundo essa autora, perfomatiza o bem-estar: "Isso significa que os professores devem ter o compromisso ativo com um processo de autoatualização que promova o seu próprio bem-estar. Só assim poderão ensinar de modo a fortalecer e capacitar os alunos." (hooks, 2017, 28). Embora esse processo tenha demandado muito esforço e investimento de tempo, energia, afeto e deslocamento, por parte desses docentes.

Incluir a subjetividade no processo de formação foi o desafio que compôs o início dessa história vivida por mim. Cheguei a Escola Bahiana em 1998 como Auxiliar de Ensino da disciplina Psicologia Médica. Reconhecida pelo professor André Peixinho, num curso de Metodologia do Ensino Superior e acolhida pela Profa Malu Soliani, professora de psiquiatria e companheira do então Coordenador Geral e querido Prof. Humberto de Castro Lima. Hoje, sou professora titular do Programa de Pós-graduação de Medicina e Saúde Humana - onde também me qualifiquei e concluí meu doutoramento - Coordenadora e docente do Mestrado Profissional em Psicologia e Intervenções em Saúde. Um programa germinado ao longo desses 20 anos no curso de psicologia.

Quando comecei essa jornada ansiava por me fazer professora. Tinha sólida experiência em clínica e dois filhos pequenos. Esses, por serem fruto de uma união multirracial, tinham pele clara e me ensinaram sobre o racismo e consequentemente a me colocar como uma mulher negra. Para Neusa Santos (2008) "saberse negra" é uma construção que implica o reconhecimento da experiência de ter sido subalternizada em sua identidade, constrangida com expectativas alienadas, colonizadas. Como professora, vivi algumas vezes, a experiência corporal desse racismo, ora de forma explícita, ora implícita. Entretanto, essa mulher negra, meio hippie, sonhadora, psicanalista de formação, estava sintetizada em mim numa robusta possibilidade de transgredir e em um permanente desejo de transformação, de se desacomodar e produzir mudanças. Na Bahiana, do século XX, existir assim não era fácil. A estrutura de funcionamento e a lógica educacional arcaica pressupunham obediência. Aqui e ali, a Dra Malu, já realizava pequenas transgressões - escutando as dores de existir dos estudantes, oferecendo metodologias de ensino alternativas - e encontrou em mim uma parceira-discípula, disposta a escutar e criar com alegria e afeto.

O início do século XXI trouxe a expansão da Bahiana, com a implantação de novos cursos. A professora Malu se transmutou em Dra Maria Luisa, nossa atual reitora. Uma mulher com grande competência de tecedeira: tecia redes complexas de mudanças e de possibilidades; realizava enfrentamentos corajosos, coordenava centenas de homens de jaleco-engravatados que investiam na docência como um luxo para seus currículos. Trazia as evidências quanto ao sofrimento dos estudantes e a responsabilidade da formação sobre isso. Naquele momento, o ambiente de formação em medicina já era reconhecido como um território estressante e promotor de múltiplos efeitos negativos na vida psíquica, no desempenho acadêmico e na saúde geral dos estudantes (Saravanan \& Wilks, 2014). Havia uma narrativa, quase vingativa, sobre a necessidade de sofrer para poder aprender. Lembro-me de estar em uma reunião de professores falando sobre a importância do cuidado com a saúde mental dos estudantes e ouvi um importante catedrático dizer: Mas pra ser médico tem que sofrer. Eu sofri e tô aqui, eles também podem sofrer.

Nessa trilha, de inclusão da subjetividade em seu currículo, a Escola Bahiana de Medicina e Saúde Pública - EBMSP, sob a batuta da Dra Maria-Malu-Luisa, foi inventando uma espécie de bahianidade, própria. Um modo de operar o trabalho formativo a partir de valores éticos, humanistas, colaborativos, que afirmam a circulação de afetos no quotidiano do processo de educação, no modus-vivendi de atuar organizacional, social e relacionamento. Uma pedagogia engajada como propunha bel hooks (2017), mas com engajamentos datados pelas narrativas em saúde ampliada, da saúde compreendida para além da ausência de doença e na garantia da saúde como direito e autocuidado, uma potente dimensão de transformação. Hoje, esse engajamento, já demanda novos ancoramentos e eles começam a ser desenhados nas discussões sobre o racismo, na contratação de pessoas trans, nas propostas de revisão curricular.

Baianidade é uma expressão que remete à identidade cultural do povo da Bahia. É uma invenção narrativa que se divide em duas etapas: na primeira metade 
do século XX, com Jorge Amado, Dorival Caymmi e um pouco mais adiante com João Gilberto - construiu-se um ideal de terra ensolarada, sensual, com traços preguiçosos e forte presença da população negra valorizando suas raízes. A segunda etapa - já apropriada pelo potente poder de impregnação do neoliberalismo - acontece num mundo globalizado, conectado (Castro, 2010). Os governantes então constroem a imagem de uma baianidade carnavalesca, ativa, musical, desconectada das raízes, pois de natureza globalizada, e entregue a uma imagem que contribui para um crescimento econômico que atribui um certo imaginário (Nova \& Fernandes, 2019) modo de existir do povo baiano, definido pelo saudoso Gey Espinheira (2001) como "modo de ser confusional". Narrativas performatizadas no cotidiano desse povo, dessa cultura, dessa economia e eternizada na poesia de Morares Moreira:

Ah! Imagina só que loucura essa mistura Alegria, alegria é um estado que chamamos Bahia De Todos os Santos, encantos e Axé, sagrado e profano, o Baiano é carnaval (Moraes, Moreira - Chame gente)

A instituição Escola Bahiana, da mesma forma perfomatiza sua própria bahianidade. Enquanto as universidades brasileiras se internacionalizavam, buscavam excelências de processos administrativos standards globalizados que banalizaram os sentidos de educar, entregues a potência destrutiva neoliberal, a Bahiana optou pela singularização, por performar numa posição de contracultura. Invadindo os congressos brasileiros de educação em saúde na busca de qualificação, observando as experiências, especialmente no Sudeste, devorou saberes produzido aqui e ali. Num exercício antropofágico, regurgitou formas nordestinas de ensinar e de aprender. Validando uma antropofagia cultural, como afirmava Mario de Andrade (1928):

"Contra todos os importadores de consciência enlatada

A alegria é a prova dos nove. A luta entre o que se chamaria incriado e a criatura-ilustrada pela contradição permanente do homem e o seu Tabu. 0 amor quotidiano e o modus-vivendi capitalista.

Antropofagia. Absorção do inimigo sacro. Para transformá-lo em totem. A humana aventura. A terrena finalidade. (...) Afetivo, o amor. Especulativo, a ciência. Desvia-se e transfere-se. Chegamos ao aviltamento. (...)

Peste dos chamados povos cultos e cristianizados, é contra ela que estamos agindo. Antropófagos."

(Mário de Andrade, 1928)
As narrativas sobre a humanização da prática profissional e das ciências foi produzindo novos sentidos do ensino, a partir da ideia de trabalho colaborativo, da circulação de afetos. Emerge assim esse elemento que estou nomeando de Bahianidade. Um modo próprio de pensar os currículos, de operar os modos de trabalho, com tecnologia e boa gestão.

Em 2004, o Ministério de Educação, implanta um novo modelo de avaliação denominado, Sistema Nacional de Avaliação da Educação Superior (SINAES) responsável pela análise das instituições, dos cursos e do desempenho dos estudantes. Construído como um processo de avaliação triangulada, envolvendo coleta de informações do Exame Nacional de Desempenho de Estudantes (Enade) e das avaliações institucionais e dos cursos com o objetivo de orientação institucional de estabelecimentos políticas públicas (Ministério da Educação, 2020). Esse sistema implica a frequente visita de avaliadores institucionais de suas visitas resultavam em notas que se agregariam às notas obtidas pelos alunos no ENAD. Eram visitas tensas e temidas. Em um de seus exercícios antropofágico, alguém diz "O MEC chegou!!" numa festa institucional e entram em cena duas drag queens, vestidas de Darth Vader e recebidas com aplausos pelos docentes presentes. Metaforicamente, ali nosso totem antropofágico se instituiu, e era uma drag, que nos ensinava a seguir com alegria sem temer o que tivesse por vir. Além disso, afirmava uma dimensão de singularidade onde se reconhecia a impossibilidade de uma avaliação representada por uma nota conter nossa experiência e a potência de trabalho criativo que tínhamos.

Esse movimento antropofágico projeta a Bahianidade no território nacional como referência de qualidade de ensino, reconhecida pelo mercado de trabalho, pelos funcionários da instituição. Perspectiva que garantiu à instituição obter o primeiro lugar, por dois anos consecutivos, 2019 e 20120, no Great Place to Work - GPTW como a melhor empresa para se trabaIhar na Bahia e a $31^{\circ}$ no Brasil.

Os 20 anos do curso de psicologia, para mim, se fizeram assim, antropofagicamente. Trabalhei na implantação do curso no ano 2000, atuando como técnica do Serviço de Psicologia; fui professora da disciplina de testes por dois anos, me afastei. Posteriormente, entre 2009 e 2015, atuei como coordenadora do curso na graduação, mantendo-me transgressora alimentei formas colaborativas de gestão, configurações 
criativas para ensinar e para aprender, me fiz mestra e depois doutora escrevendo sobre essa experiência de pesquisa aplicada'.

Numa lógica colaborativa, elaboramos - eu, os professores, a supervisão pedagógica e os alunos da época - um currículo novo entre 2009 e 2010, assumindo a psicologia como uma profissão de saúde ampliada, apta a prevenir, assistir e promover o desenvolvimento de sujeitos, comunidades, cidadãos e trabalhar pela garantia dos direitos humanos. Para dar sustentação a isso, incluímos metodologias ativas conhecidas como o Problem Based Learning (PBL), ou inventamos outras como o Internato em Psicologia (Daltro \& Pondé, 2017)2. Trabalhamos, pactuamos, mediamos identidades e existências. Mas, acima de tudo, nos propomos a descolonização dos modelos hegemônicos do Sudeste de fazer formação.

Em entrevista concedida a Fernando Schüler e Mário Mazzilli na Inglaterra (Fronteiras do Pensamento, 2020), o sociólogo e filósofo polonês Zygmunt Bauman, diferencia o conceito de comunidade do conceito de rede. Para ele, a comunidade tem a função de conectar, precede ao sujeito, enquanto a rede é mantida viva, e permite a desconexão rápida. A comunidade, por sua vez, demanda laço e compromisso com o outro, inclui o tempo, empenha o futuro a rede amplia possibilidades e olhares. Assumindo uma lógica que reconhece a complexidade da experiência formativa, a Bahianidade do curso de psicologia se firmou no exercício de deslizar entre redes, com laços possibilitando uma ocupação institucional. Assim a psicologia foi se instituindo com contexto da Bahiana respondendo demandas, propondo mudanças, transgredido ali e acolá, cuidando, garantindo inclusive espaços antes reservados exclusivamente à medicina; deu sentido ao interdisciplinar. Não sem esforço ou perdas, moveu-se além dos limites de um Curso.
Em 20 anos, o Curso de Psicologia contribuiu para a consolidação dessa Bahianidade e de sua lógica contra hegemônica. Essa lógica, não necessariamente se coloca a partir dos conteúdos ofertados ou das metodologias de ensino, mas eminentemente se realiza numa lógica de coletivo-comunitário institucional que investe em laços e em afetos. Numa narrativa quase cafona, meio hippie, fala-se de amor, de um mundo melhor, de uma saúde melhor, considera-se diferenças, assegura-se estabilidade de emprego, garante-se possibilidades de criação coletiva. Em um tempo narrativo de provisoriedades, meritocracias, individualismo, essa Bahianidade forja-se numa narrativa de alteridade, que nem sempre se realiza, mas circula como possibilidade em território comunal onde o afeto entre as pessoas é estruturante.

No contexto global brasileiro, vemos expandir a categoria neoliberal acadêmica no âmbito do ensino superior brasileiro privado. Tal perspectiva dá ao mercado de capitais o protagonismo sobre as regras de gestão dos processos de formação e desloca a educação do campo do direito para o campo do negócio. Nesse cenário de precarização do trabalho docente, da dignidade acadêmica científica, a Bahiana parece colocar-se nesses últimos 20 anos como um campo de resistência.

Peço licença a meus ancestrais para usar a palavra Quilombo para falar de uma instituição eminentemente branca e recoberta de privilégios. Proponho com isso afirmar o território da educação como um território de convergências, divergências e resistências. Tomo emprestado a tradução proposta por Pepetela (1999) da palavra Quilombo, definida como" acampamento guerreiro" (Pepetela, 1999). No Brasil, esse termo foi ressignificado como comunidade autônoma de negros fugitivos, território de resistência.

\footnotetext{
${ }^{1}$ Pesquisa aplicada ou investigação aplicada método científico que envolve a aplicação prática da ciência. Pesquisa aplicada Na sequência, os trabalhos executados com o objetivo de adquirir novos conhecimentos para o desenvolvimento ou aprimoramento de produtos, processos e sistemas;

${ }^{2}$ Internato, uma prática pedagógica assistida, na qual o professor responde como mediador numa perspectiva psicopedagógica.
} 
$\mathrm{E}$, no contexto atual, me sinto cotidianamente aquilombada, trabalhando num projeto comunal de formar psicólogos e profissionais de saúde aptos a intervir na sociedade com vista a transformá-la num lugar melhor. Um projeto que se constrói e tece a partir da atuação de mulheres, cuja as subalternidades foram transformadas em potencia. Não necessariamente vivenciamos tudo isso, cotidianamente, mas a alteridade não é algo que está dado, nem a cultura do trabalho coletivo, nem a resistência... Mas são experiências que se colocam a partir do exercício... um exercício que envolve afetos e crítica e que não reconhecem o sofrimento como algo necessário, mas suficiente para dar conta de refletir sobre si, sobre o outro, sobre o coletivo. Afetos que engendraram em mim formas de viver, de ensinar e aprender.

\section{Conflitos de interesses}

Nenhum conflito financeiro, legal ou político envolvendo terceiros (governo, empresas e fundações privadas, etc.) foi declarado para nenhum aspecto do trabalho submetido (incluindo, mas não se limitando a subvenções e financiamentos, participação em conselho consultivo, desenho de estudo, preparação de manuscrito, análise estatística, etc.).

\section{Referências}

Daltro, M.R., \& Faria, A.A. (2019). Relato de experiência: Uma narrativa científica na pós-modernidade. Estudos $e$ Pesquisas em Psicologia, 19(1), 223-237. http://pepsic. bvsalud.org/scielo.php?script=sci_arttext\&pid=S180842812019000100013\&lng=pt\&tlng=pt
Macerata, I., Soares, J.G.N., \& Ramos, J.F.C. (2014). Apoio como cuidado de territórios existenciais: Atenção Básica e a rua. Interface - Comunicação, Saúde, Educação, 18(supl.1), 919930. https://doi.org/10.1590/1807-57622013.0210

Pepetela (1999). A gloriosa família: o tempo dos flamengos. Nova Fronteira. p. 407.

Daltro, M.R., \& Pondé, M.P. (2017). Internato em psicologia: aprender-a-refletir-fazendo em contextos de prática do SUS. Revista Psicopedagogia, 34(104), 169-179 http://pepsic. bvsalud.org/scielo.php?script=sci_arttext\&pid=S0103$84862017000200007 \&$ Ing=pt\&tlng=pt

Ministério da Educação (2020). Sistema Nacional de Avaliação da Educação Superior (Sinaes). http://portal.mec.gov.br/ component/content/270-programas-e-acoes-1921564125/ sinaes-2075672111/12303-sistema-nacional-de-avaliacaoda-educacao-superior-sinaes

Fronteiras do Pensamento (2020). Identidade Pessoal [Video]. https://www.fronteiras.com/videos/identidade-pessoal

Saravanan, C., \& Wilks, R. (2014). Medical students' experience of and reaction to stress: the role of depression and anxiety. Scientific World Journal, 2014:737382. https://doi. org/10.1155/2014/737382

Souza, N.S. (1948-2008). "Tornar-se negro"- As vicissitudes da Identitade do Negro Brasileiro em Ascensão Social. Graal.

Andrade, M. (1928). Abre-alas. Revista de Antropofagia, 1(1), 1-96. https://digital.bbm.usp.br/bitstream/ bbm/7064/1/45000033273.pdf

Nova, L., \& Fernandes, T. (2019). Baianidade. Mais Definições em Trânsito. http://www.cult.ufba.br/maisdefinicoes/ BAIANIDADE.pdf

Castro, A.A. (2010). Axé music: mitos, verdades e world music. Per Musi, (22), 203-217. https://doi.org/10.1590/S1517$\underline{75992010000200017}$ 